\title{
Perceptual objectivity and the limits of perception
}

\author{
Mark Textor ${ }^{1}$
}

Published online: 12 April 2018

(C) The Author(s) 2018

\begin{abstract}
Common sense takes the physical world to be populated by mindindependent particulars. Why and with what right do we hold this view? Early phenomenologists argue that the common sense view is our natural starting point because we experience objects as mind-independent. While it seems unsurprising that one can perceive an object being red or square, the claim that one can experience an object as mind-independent is controversial. In this paper I will articulate and defend the claim that we can experience mind-independence by mainly drawing on the work of the Gestalt psychologist Karl Duncker who, in turn, built on Husserl's work. In the development of this claim the notion of a limit - either a maximum or minimum - of perception will play an important role.
\end{abstract}

Keywords Perceptual constancy · Object constancy · Husserl · Duncker · Conrad Martius

\section{Early phenomenologists on objective experience}

We can introduce our topic by comparing and contrasting two cases ${ }^{1}$ :

(A) You look up at the night sky and I have a visual experience as of many stars twinkling.

(B) You bang your head hard and 'see stars'.

We could say, without yet putting any explanatory weight on it, that in (A) you have an experience as of a multitude of objects that seem to you to be out there to be encountered. In contrast, in (B) there is a multitude of 'things', but they don't seem to you to be 'out there' to be encountered. Let's call an experience of the kind you have in

${ }^{1}$ I borrow the example from Siegel 2006, 402.

Mark Textor

Mark.Textor@kcl.ac.uk

1 Department of Philosophy, King's College London, WC2R 2LS, London, UK 
(A) an 'objective experience'. An objective experience is not just an experience of something that exists independently of any mental activity but that also (purports to) represents its object(s) as mind-independent.

Several early phenomenologists argued that we have such objective experiences. Here are four examples that will help to anchor our discussion. ${ }^{2}$

First, Paul Linke (1876-1955) wrote with reference to an example given by the Munich phenomenologist Hans Cornelius:

Even the immediately perceived Corneliusian grey spot is given to me as something independent from me whether it is real or not. (Linke 1918, 124; my translation.)

If a surface looks to me as if there is a grey spot on it, it seems to me as if there is a spot 'out there', whether there is one or not. I experience the spot, in Linke's terminology, as 'extraneous to me' ("ichfremd") and 'extraneous to the act of perception ("aktfremd") (ibid.).

Second, Roman Ingarden (1893-1970) asked his readers to consider perceiving a red ball:

The ball has - if it exists at all - its own being [Eigensein], and it is for the ball completely accidental that it is perceived by someone. It suffers no changes in virtue of the fact that it is perceived and it is given as such an object that continues to exist in space after we have closed our eyes and no longer perceive it. (Ingarden 1930, 272-3, my translation and emphasis.)

The ball does not only exist without being perceived, says Ingarden, it is given to the perceiver as something that would persist in space if it were not (no longer) perceived. We experience the ball as something that is disposed to go on existing independently of our experience of it.

Third, the Gestaltpsychologist Karl Duncker (1903-40) called non-epistemic visual perception 'visual participation': perceiving is a form of participating in the changes and being of an object. This terminology may strike one as idiosyncratic but we can easily reformulate Duncker's statements without it. He writes:

Visual participation requires, first of all, the object in which we participate. In the very nature of participation as such lies the independence, the being-in-itself of this object with reference to the act of participation. In other words, participation in an object is not creation of the object. Beyond this, it is characteristic of visual participation (in contradistinction to many another type of participation) that the object remains untouched phenomenally. The tree enters my vision and leaves it; but it does not, for that reason, change qua that tree. The world of objects is experienced as "unverändert durchgehend," as "persisting unchanged" ("objectconstancy"). The phenomenon of being-in-itself and of persisting unchanged

\footnotetext{
${ }^{2}$ Duncker, Linke and Conrad-Martius will figure later in Merleau-Ponty's Phenomenology of Perception. In this paper I will focus on the former authors.
} 
is the objective correlate of the phenomenon of (merely-) participating-in.

(Duncker 1947, 506-507, my emphasis.) $)^{3}$

A page later, Duncker sums this up by stating that 'the objective world is experienced as transcending the temporal and spatial limits of vision, as "persisting".'

Duncker introduces here the concept that will be the key to understand objective experience: the concept of the limit of perception. When we have a perceptual experience as of an object, we are aware in our experience of the limits of our contact with the object and can experience the object 'transcending' these limits. We can experience the object as persisting beyond the limits of our perception. The phenomenon of persistence is not restricted to vision (ibid). There is an experiential difference between an auditory experience as of a note gradually softening and finally ceasing on the one hand and an auditory experience as of a note that is played with the same volume gradually becoming less distinct on the other hand. In the second case we experience the note as transcending or persisting beyond the limits of our auditory experience.

Having such an objective experience is independent of the perceiver's beliefs about the object of their experience. To make the belief-independence of objective experience plausible, think of your perceptual experience of the ball. I tell you that you are participating in a psychological experiment and that you will be undergoing an illusion of seeing a ball rolling away from you because you took hallucination inducing drugs. In fact you do see a ball rolling away from you; I misinformed you: there is no experiment at all. In this situation you will have an experience as of the ball as persisting when it rolls too far away from you to see it. Since your belief that you are undergoing an illusion prevents you from applying your beliefs about the ball, the appearance of persistence must indeed be a matter of how things visually seem to you.

Fourth, when speaking of 'phenomenal autonomy of persistence' Duncker refers, like Ingarden before him, to Hedwig Conrad -Martius. Conrad-Martius coined the suggestive term, 'phenomenal claim to autonomy of being' ('phänomenaler Anspruch auf Daseinsautonomie'). ${ }^{4}$ In perceptual experience, objects make a claim on us to be perceived as existing independently of our perceptions. One way they do so is that we experience the limits of our experience of some objects; another way is that we encounter objects that were beyond the limits of our experience. When you walk around the corner it seems to you that you encounter objects that were there all along. Again the experience of a limit of your experience and what lies beyond it is needed to make sense of an experience of encountering an object that was there all along. Conrad -Martius discussed this aspect of objective experience in detail and I will come back to her work in section 6.

I hope the four descriptions resonate with the reader. If these authors are on the right track, we not only perceive mind-independent objects, sometimes we experience a mind-independent object as being mind-independent: in our experience of it we experience the object's persistence beyond the limits our perceiving. The main task of this paper will be answer the question what the experience as of an object be like for it to be an experience of an object as well as an experience of its own limits.

\footnotetext{
${ }^{3}$ According to the editor of Duncker's paper, the paper was written in the 1930s.

${ }^{4}$ See Conrad -Martius (1916, 413) and Duncker $(1947,509)$.
} 


\section{Perceptual constancy as a model}

Common sense has it that perceiving an object depends on a number of factors: the perceiver is in the right position with respect to it, she is not too far or too close to the object, the illumination is right etc. Evans (1980, 261ff) envisaged that these conditions are collected in a rudimentary theory of perception. The folk theory of perception will contain conditionals such as

If $\mathrm{x}$ moves behind $\mathrm{y}, \mathrm{x}$ will no longer be perceived.

If $\mathrm{x}$ moves some distance from a perceiver, it will no longer be perceived.

If the perceiver is distracted, $\mathrm{x}$ will no longer be perceived by her.

If the light is too bright (dim), $\mathrm{x}$ won't be perceived.

If some of these conditions are not satisfied, the object will not be perceived. But it would be perceived again, if they were fulfilled. Our grasp of what it is to be mindindependent consists in our knowledge of factors on which our perceptual experience depends and which put limits on it. If we were perceptually aware of the limits of our perception, we could experience our perception of an object depending and transgressing them. This would amount to an experiential awareness of mindindependence.

A well-known phenomenon makes it plausible that we are indeed perceptually aware of factors on which our perceiving of an object depends: perceptual constancies. Let us consider two examples:

(A) Colour constancy: When the illumination changes a white surface still looks white although it seems brighter than before. The colour looks the same; the illumination, a condition for perception, seems to change.

(B) Size constancy: I walk towards a tower. When I approach the tower its visual manifestation expands: it occupies more and more of my visual field. Yet the tower does not appear to change in size: it looks the same size. In turn, it seems to us that the distance between us and the object is decreasing. ${ }^{5}$

Both (A) and (B) are examples of, to use Hopp's $(2011,149)$ helpful formulation, 'a feature appearing differently under different conditions while not appearing to be different'. In the perceptual processes described in (A) and (B) we experience changes in the factors mentioned in the folk theory of perception. In an extended perceiving my seeing the tower while I approach it - we experience the change of an intervening factor - here, the distance between us and the tower - as well as the constant size of the object to which we attend in perception. Duncker's description of the perceptual constancy phenomena is therefore spot on:

These facts prove that there are other cases in which a living being (not only man) spontaneously experiences certain phenomena as characteristics, not of things, but of an intervening factor. (Duncker 1947, 539)

\footnotetext{
${ }^{5}$ Thanks to a referee for helping me to improve these sections.
} 
In general, if a perceptual system enables the perceiver to experience changes in relations between the perceiver and the object of perception (the intervening factors) and thereby to experience that the existence and character of her experience depends on the holding of these relations, the perceiver can experience objects as being independent of his actual perceptions. ${ }^{6}$

\section{Experiencing mind-independence}

We can now use these ideas to make progress with objective experience; the experience of something as mind-independent. In order to experience something in this way, it does not suffice to have an experience of an object as independent of our actual perception. It must perceptually seem to us as if the object persists while our perceiving of it reaches its limit: we need to have an experience as of an object persisting beyond the limits our perceiving. Are there such experiences?

Yes, answered Duncker:

Just as, under certain circumstances, a darkening is experienced as a diminution of illumination rather than as a darkening of the object color, just so a disappearance or a fading is under certain circumstances experienced as the cessation or as a diminution of participation, not as disappearance or fading of the object. (Duncker 1947, 540)

You can experience a fading either as a change in an intervening factor - a change in the relation to the object is experienced, while the object does not seem to change - or as a change in the object - a gradual ceasing to be - while the intervening factors seem not to change. If one is able to have experiences of the former kind, one will be able to experience the mind-independence of an object. We experience the object as constant through experienced changes of conditions of perceivability - perceptual constancy and we experience the object as constant through changes beyond a limit of perceivability: mind-independence. In experiences of the second kind something, an object or process, seems to persist, while our perceiving reaches a limit. Such experiences are the basis for our understanding of mind-independence. We get a sense that the object of perception persists beyond the limits of perception. I will come back to the notion of an objective experience in the next section.

Cassam recently rediscovered this idea. He pictures himself walking towards and then past a tree in a quad:

As I keep walking, the tree eventually recedes until at some point I can no longer see it. To experience the tree as receding from view is not to experience it as diminishing in size. Receding is not the same as ceasing to exist, and the experience of an object gradually disappearing from view is not the experience

\footnotetext{
${ }^{6}$ See also Smith (2002), 175. Burge $(2010,408)$ takes perceptual constancies to be capacities whose exercises need not be conscious perceptions in which, for example, an object/feature appear different yet manifestly the same. Because Burge is not concerned with how things seem to the perceiver, but with the states of a subpersonal system, I will set his account aside in this paper. See Campbell $(2011,272-3)$ for criticism of Burge's conditions for perceptual objectivity.
} 
of it gradually ceasing to exist. My experience represents the tree as persisting as my location changes and I move away. (Cassam 2014, 162)

Cassam uses this observation to address what he and John Campbell call 'Berkeley's Puzzle': how do we acquire concepts of mind-independent objects in the first place? The answer is straightforward, says Cassam: our experience represents some things as mind-independent and we can abstract the concept from there.

In the next sections, we will not assess whether this is the way to solve Berkeley's puzzle, but what, in general, the case must be for one to have experiences of one's perceiving of a persisting object 'diminishing'. If Duncker is on the right track, we can answer this question in part by drawing on what we know about perceptual constancy. ${ }^{7}$ However, we will see that we need to go beyond the concepts necessary to describe perceptual constancies to understand what it is for an object to appear mind-independent.

\section{Perceptual anticipations and perceptual maxima and minima}

There is an experiential difference between experiencing the perishing or dissolution of an object and experiencing the worsening of one's perceiving of an object that continues to exist beyond our perceiving. What must experience as of objects be like to allow for this difference?

In the background of the work of authors in the phenomenological tradition is Husserl's answer to this question. So let's have a look at it. Husserl's work on perception is fueled by discoveries about perceptual constancies. For example, colour constancy was explored by a number of psychologists, such as Hering (1905), Katz (1911) and Gelb (1929). They influenced Husserl and he influenced them. ${ }^{8}$ Husserl is concerned with the experiential side of perceptual constancies:

Different acts can perceive the same and yet sense different things. The same tone we hear once spatially near and once far. (Husserl 1913b, 381; my translation) ${ }^{9}$

\footnotetext{
${ }^{7}$ Duncker $(1947,541)$ himself argued that a more satisfactory explanation of phenomenological objectconstancy can be given by appealing to a number of facts about voluntary movements. For example, the voluntary act of opening your eyes is not experienced as causing a change in the properties of the objects that come into view. However, such facts seem to be too contingent to yield a general explanation. There is nothing like voluntarily opening your ears. Yet a being that had only auditory experiences could still experience some objects of perception as mind- independent.

${ }^{8}$ Katz took courses with Husserl from 1904 to 1906; see Schuhmann (1977, 80). Husserl read and commented on Hering's work in 1909, in connection with the dissertation of his student Heinrich Hofmann; see Hofmann (1919) (see Schuhmann 1977, 129ff).

${ }^{9}$ Husserl frequently describes perception of an object interpretation of non-intentional sensations or 'hyletic data' (see, for example, Husserl 1913b II/1, § 2). Husserl's dichotomy between data and interpretation gives rise to a number of exegetical and systematic questions (see, for instance, Linke 1928, § 68). Are hyletic data elements of our sub-personal or personal psychology? How does interpretation work? Are the sensations 'building stones' out of which a perception of objects is constructed, as Duncker (1947, 517 Fn.) and Burge $(2010,130)$ think? Or are they posterior abstractions from a perceiving, as a more charitable reconstruction might hold? For the purposes of this essay we can set these questions aside. Dunker and Linke, for example, follow Husserl in taking perceptual constancies to hold the key to understanding objective representation, yet explicitly reject that objective experiences are constructed or derived from something prior.
} 
One can distinguish in an extended perceiving different phases. But throughout its different phases the identity of the object perceived is manifest, although it appears differently in different phases. The question is what links the different phases of such an extended perceiving perceptions together.

Husserl's answer, in essence, is that it seems to us that we perceive one and the same object through changes of appearance because our experiences are connected to intentions that have conditions of fulfillment. It is tempting to construe these intentions as expectations, that is, beliefs about perceptions one will have at a later point in time. Husserl is adamant that this temptation needs to resisted:

Intention is not expectation; it is not essential to it that it directed towards a future realization. (Husserl 1913a, b II/2, 40; my translation)

Husserl motivates the distinction between intention and expectation with a suggestive example. ${ }^{10}$ You see a carpet with a particular pattern on it, but part of the carpet is hidden by a piece of furniture. In this case 'we, as it were, feel that the lines and colour patterns continue 'in the sense' of what we have seen' (1913b II/2, 40; my translation.). But we have no expectations about how the pattern will look if we go on perceive the parts hidden from us; we know that we can't perceive these parts. The intentions under consideration - I will follow the literature in calling them 'anticipations - differ from expectations, but they can prompt expectations. If we just look at an object in front of us without intending to move closer or around it, we anticipate how other parts of the object look. These anticipations prompt expectations about how the object will appear to us when we start to move in relation to the object of perception. ${ }^{11}$

In the visual case, anticipations are pictorial clues or suggestions (bildliche Andeutungen). Take the carpet pattern example: the look of the pattern suggests how its hidden parts look. Similarly, if I see the front of a cubus, some of its parts are seen well others poorly. My current view of the cubus is a good view of its front as well as a poor view of its side. ${ }^{12}$ Yet, the poor view of its side is still a view of its side. The poor view of the side suggests to me a better view of the side under differ conditions. The look of the object from one perspective gives you a clue how it looks from a different perspective: it looks to me such that I can get a better view of its side if I change my position. ${ }^{13}$ Such clues can be confirmed or fulfilled in further perceptions. When one changes one's position, it seems to one that one is seeing something better that one has already seen poorly.

Perceptual anticipations are, in general, fulfilled in further perceptions and we experience their fulfillment:

The prior intention was directed on the same object as the current one, but what was only unclearly suggested in the first intention is now itself given, or at least more clearly, more richly, obviously more adequately given and thereof we have an immediate awareness, we experience the fulfillment of the suggestion as a

\footnotetext{
${ }^{10}$ On this see Madary (2010), 148.

${ }^{11}$ See Husserl (1913b) II/2, 40-1.

${ }^{12}$ See Husserl (1904/5), 50. Husserl (1904), 36-7

${ }^{13}$ See Smith (2002), 135. Kelly (2010) goes a substantial step further and argues that one must be driven to get a better 'perceptual grip' on the object.
} 
peculiar feature of the new perception or, respectively, as a unity creating moment in the succession of acts. (Husserl 1898, 144. My translation and emphasis.)

Husserl's description strikes me as spot on. When you see the sides of the book better, you sometimes feel that things look as they should look. This feeling is, in part, negatively characterised as the absence of surprise. ${ }^{14}$ When one has this feeling, one experiences some acts as belonging to one extended perceiving.

Some of our perceptions are tied together by chains of anticipations and experienced fulfillments to an extended perceiving of one object. In such an extended perceiving we experience sameness of object through manifest changes of perception. If the anticipations concern changes of conditions - how the object will look if we move closer or change our position relative to it - and we experience the fulfillment of the anticipations, we experience perceptual constancy. It seems to us that we perceive the same object from a different side, from a better perspective or from closer up. The interplay of anticipation and experienced fulfillment makes it possible to have an experience of manifest sameness of an object perceived through changes of appearance. It is the person-level counterpart to the requirement that the perceptual faculty 'locates' some perceived changes in changes of the conditions of perception. ${ }^{15}$

This interplay of anticipation and experienced fulfillment is absent in what Husserl calls 'adequate perception'. The following example, in which a tone - an objective particular - and the hearing of the tone are contrasted, helps us to see Husserl's distinction between adequate and inadequate perception:

An emotional experience has no adumbrations. If I turn my gaze on it, I have something absolute, it has no sides that represent themselves once in this, then that way. [...] In contrast, the tone of a violin with its objective identity is only given in adumbrations; it has its changing appearances. These differ depending on whether I approach or move away from the violin, whether I am in the concert hall or listen through closed doors etc. No appearance is privileged as the absolute one. ... (Husserl 1913b, 81. My translation.)

Emotional experience serves here as a representative example of experience in general. 'Adumbration' is Husserl's term for the appearances of external objects: such objects are given only in adumbrations; objects of this kind adumbrate. Other objects, experiences, that is, mental acts and activities, don't adumbrate (see Husserl 1913b, 77). Consciousness of one's present mental acts suggests no further acts of awareness in which anticipations are fulfilled or 'disappointed'. For this reason, Husserl calls it 'absolute'. Consider further emotions. Your awareness of your anger does not suggest further acts of awareness to you in which the anger is perceived better. You may have inductive knowledge that your raging anger will abate soon and change into a less violent emotion. But this expectation is not suggested by your present awareness of anger. It is simply general knowledge that you have about your emotional propensities.

For our purposes it is important that we not only anticipate how an object would look if the conditions of perception change, but also anticipate the diminishing and

\footnotetext{
${ }^{14}$ See Mulligan (1995), 204.

${ }^{15}$ See Madary 2010, 149.
} 
extinction of our perceiving of an object under some changes of these conditions. For if it seems to us that an object can be perceived better if some factors change, it also seems to us that an object can be perceived worse if those factors change differently. The improvement and worsening of our perception has a limit. If, for example, I move closer to an object I will see its colour better, there will be a distance to the object where I see the colour as best as it can be seen for my purposes. If I go even closer, the colour will go out of focus. My perceiving the object contains anticipations to this effect. There is, then, a positive maximum of perception ("Maximalpunkt") of perceiving that is also a turning point: if you go beyond the point your perception of the object worsens. ${ }^{16}$ There is also a worst point of perception ("Minderungsgrenze") beyond which we lose perceptual contact with the object. ${ }^{17}$

In his 1907 Husserl spends paragraphs 35 to 38 to resolve the tension between the idea that there are maxima and minima of perception and his view that there is no adequate perception of an object. Yes, there is no adequate perception: we can't perceive the object as it is because we can only perceive it in adumbrations. But there is still a maximum of perception. For our human constitution and interests determine maxima and minima of perception. By nature perception is a process that cannot result in adequate perception, but there is best perception for beings like us relative to a given interest in the object perceived.

In a perceptual experience of an object, we anticipate how our perceiving of the object will improve as well as how it will worsen with respect to such a limit. Because we anticipate our perceiving of an object to worsen if certain factors change and approximate a minimum or improve until a turning point is reached, there is an experiential difference between an experience as of an object 'decaying' and an experience as of an object persisting beyond the limits of perception. If we experience the fulfillment of such 'negative anticipations', it seems to us that we cease to perceive a persisting object.

\section{A minimal notion of objective experience}

The last section suggests that an experience as of an object is an objective experience if, and only if, it involves anticipations about how it can be improved and worsened in relation to a maximum (minimum).

For an experience to be objective it is not necessary that one actually experiences the fulfillment of such anticipations. The anticipations are enough to have an objective experience. ${ }^{18}$ Why? Because of the anticipations, it seems to us that if some conditions of our present perceiving change beyond a limit, our perception of the persisting object will diminish and finally cease. This seeming and not its actual fulfillment makes for perceptual objectivity.

To see the point of this clarification of the notion of an objective experience consider an 'experience' in which something seems mind-dependent to you. You have tinnitus.

\footnotetext{
${ }^{16}$ See Husserl $(1904 / 5) \S 14$.

${ }^{17}$ See Husserl (1907), 107.

${ }^{18}$ See Husserl (1913b), II/2, 41. See also Siegel (2006, 401), who stresses that for what she, following Smith (2002), calls 'perceptual consciousness', it is sufficient that something looks as if one's experience of it will change under certain conditions.
} 
You hear a ringing 'in your ears' for an hour. When you are aware of the ringing, you don't have perceptual anticipations. The auditory experience does not seem to become better or worse in response to changing conditions of perceptions. There is nothing like the experience of fulfillment of positive or negative anticipations. ${ }^{19}$ There is no experiential distinction between your awareness of the ringing becoming fainter while your experience is clear and your experiencing worsening while the ringing persists unchanged. You may have inductive knowledge that the ringing stops after roughly $30 \mathrm{~min}$ or that the extent and intensity of it depends on your blood pressure. Such inductive knowledge will enable you to predict how and when the ringing will persist, but such expectations are not perceptual anticipations. It does not seem to you that the ringing will soon stop or get more intense; you have propositional knowledge about changes of your experience, but this is not a case of perceptual objectivity.

The notion of objective experience discussed so far minimal because it leaves open substantial questions about perceptual objectivity. To see this compare it with Siegel following explication of what she calls an experience with perceptual phenomenology:

An experience is perceptual if it seems to one that if one moves one's sense-organ, one's perspective on the [odor/thing seen] can thereby change. (Siegel 2006, 401)

An experience has perceptual phenomenology if experience represents an object as independent from the perceiver, roughly, as out there to be met. If I have an after-image, I have no perspective that seems to change in response change to movements of my sense-organs.

According to Siegel's necessary condition for objective experience, only experiences which can make us aware of changes in spatial relations between us and the object perceived can be objective. For the movement of our sense-organs changes spatial relations between the object of perception and these organs. Now, there are no doubt anticipations relating to distance and orientation involved in many objective experiences. If sensory experience had no spatial content, we could, for example, not experience some changes in how things seem to us as changes of distance or orientation etc. $^{20}$ But is it part of our concept of experiential objectivity that an experience is only objective if we have anticipations of how the object would appear to us when we change the orientation or distance to it? According to the minimal notion, the answer is NO. An objective experience is an experience that comes with anticipations about improvement and worsening in response to changes of some conditions. But it does not identify these changes as movements of the sense-organs or, more generally, changes in spatial relations. The conditions may be non-spatial.

Here is an example that makes the minimal condition plausible. In colour constancy the colour of an object 'looks differently' under different illumination 'without appearing to be different' (Hopp). Now, the illumination may change without you moving your senseorgan. To make this vivid consider a situation in which you can only stare at the

\footnotetext{
${ }^{19}$ Sometimes rainbows are listed as sensory or mind-dependent objects. See Evans (1982, 263). Our experience of a rainbow comes with perceptual anticipations, but these anticipations will be disappointed. The rainbow looks like something out there to be met in space, but it isn't.

${ }^{20}$ See Cassam 2014, 166.
} 
coloured surface without changing your orientation towards it or even moving your eyes. If your perception of the object contains perceptual anticipations of how the surface colour will look better or worse if more or less light is on it, you have an objective perception of it. $^{21}$ The surface colour seems to persist beyond the limits of your perceiving, although the limits are not approached by moving your sense-organs. Imagine further that you are able change the ambient light without moving any of your sense-organs. If you change the light, some of your anticipations will be satisfied or disappointed; the colour looks as you anticipated it would look. Now, if your anticipations are fulfilled or disappointed in this situation, they are not anticipations about how the perception of the surface will be improved/worsened in response to movements of a sense-organ. For your sense-organs have not moved and, hence, anticipations that involve their movement cannot be fulfilled or disappointed. Yet, the anticipations that you have seem to suffice to make an experiential difference between ceasing to see a constant colour and seeing a colour fading away. You will of course also have perceptual anticipations that concern improvements/ worsening of perception in response to movements of your sense-organs. But the example shows that it is not part of our conceptual understanding of an objective experience that such an experience 'comes with' anticipations relating to changes in space.

The last point can be strengthened by considering a case in which we cannot have anticipations about improvement/worsening of our perceiving in response to movements of our sense-organs. Imagine that you hear a melody. Husserl brings out that a form of anticipation is involved here:

While the first tone is sounding, the second follows, then the third. Are we not forced to say: when the second tone sounds, I hear it, but no longer the first? Therefore I never really hear the melody, but only individual tones. (Husserl 1928, 385; my translation)

We hear the melody and in order to do so we must still 'hear' the tone that we heard before when it no longer sounds. We hear the tone as the same, although it 'fades out' and appears therefore differently. Here we have at least a prima facie case of an objective (auditory) experience in which our anticipations don't concern movement of sense-organs. We anticipate a different, less clear appearance of the tone as time passes, independently of the movement of any sense-organ. The object of the perception is the same, but our perceiving of it approaches a temporal limit. Whether we indeed have an objective experience in this case should be assessed in the light of further reasons and not simply be ruled out by our notion of objective experience. The minimal notion allows us to assess these cases and is therefore preferable. It does not commit us to hold that the objects of experience need to have a spatial location. For example, it is an open question whether a sound has a spatial location; yet it can be the object of an objective experience.

\footnotetext{
${ }^{21}$ According to Smith, spatial relations are indirectly involved in colour constancy: '[T]he varying sensations indicate to us a changing relation to the perceived object to something else in space' (Smith 2002, 175). There is more light over here than over there. So light seems to occur in spatial regions in various quantities and we experience the object to the light that surrounds it. While plausible, this does not help to defend the account of perceptual consciousness in terms of movement of sense-organs. I am grateful to a referee for making me think more about the relations involved in perceptual constancy.
} 


\section{Further limits of perception}

Husserl provided the main conceptual tools to understand perceptual constancy. In the previous section we used, following Duncker's example, these tools to shed light on the notion of an objective experience. But appealing to perceptual anticipations and fulfillments is insufficient to capture the full range of perceptual experiences in which an object seems mind-independent to us. For not only do we have experiences of a persisting object going out of 'view', we also have the experience of an unseen object coming into 'view'. When I turn the corner, I have an experience of encountering the car that was there all along; I don't have an experience of the car coming into existence. This cannot easily be explained with the same apparatus that was introduced for perceptual constancy. There is no extended perceiving in which intervening factors seem to change, sometimes beyond 'breaking point'. There is an onset of a perceptual experience in which something seems to be already there.

This kind of experience is discussed in detail by Conrad -Martius:

[I]f we posit the case that we turn around in unfamiliar surroundings, the now newly perceivable objects are not "suddenly" there without any intuitive relation to the previously perceived objects, simply added to them. Rather the in peculiar way empty spatial reality which was previously co-given [mitgegebene] with the sphere of perception fills itself with them. (Conrad Martius 1916, 381; my translation)

Even if the scene before my eyes is occupied by a house, the space beyond the house is co-given but not seen. It seems, therefore, that I encounter something that occupied a location that exists independently of my perception when I walk around the house and see the parked car beyond it. In order for us to have such perceptions, we must be aware of space although we don't see it.

Conrad Martius argues that the co-givenness of something beyond the limits of one's perceiving is a general feature of how the external world is given to us in perception:

In all cases where I am at all directed into the external world, I am directed with my intuition somewhat over the limits of my sphere of perception. (Conrad Martius 1916, 381)

How must experience be like to be directed beyond its own limits? Space seems not to end where our perceiving 'gives out'. We have such experience because the limits of perceiving are manifest to us in perception: Duncker gave a good description of this phenomenon as the limits of perceiving 'presenting themselves' to us:

The limit of participation does not, in general, present itself as a sharp contour, but as a peculiar reaching-no-further, of which we frequently do not become conscious until new objects enter. (Duncker 1947, 511)

When it seems to me that there is white vase in front of me, it also seems to me that there is more to be seen to the left, right and behind the vase, but my perceiving does not reach that far. It is part of the phenomenal character of our experience that it seems 
to us to have limits and that these limits are not limits of the objects of perception. ${ }^{22}$ It seems that scene before our eyes does not stop where our vision cannot reach. ${ }^{23}$ Again, this is not a belief in unseen regions of space, but a perceptual seeming. In the figure on the previous space, it just looks as if there is part of the figure hidden from view.

With this in mind, we can make sense of the kind of experience that has so far escaped us. We have the experience of a formerly unperceived object coming into view and not of an object coming into existence, because we are aware of the limits of our perceiving and now experience a change in the limits of perception, not in the world we perceive.

There is, then, an analogy between the two cases of object constancy. In both cases, we experience the limits of our faculty. Once we experience some enabling condition for perception changing beyond a limit, we experience a change in the limit of our perceiving such that something which was located in a region beyond our previous limit is now within the new limit, either because the object or we changed location. In general, our awareness of our limits of our perceiving enables us to have experiences of objects as mind-independent.

\section{Conclusion}

Objective experience is a matter of limits of perception being perceptually manifest in the perception they are limits of. In some experiences, we are aware of an object and how the limits of our receptivity bear on our experience. If this idea is along the right lines, things are given to us as mind-independent before we have acquired the corresponding concept of a mind-independent object. Human and nonhuman animals can therefore both have objective experiences. Hence, they experience the world as containing persisting mind-independent objects. The picture of the world as containing mind-independent particulars with 'biographies' is our natural starting point because it is how we experience the world. A revisionary metaphysics that dispenses with objects of this kind beggars belief because it does not sit with our experience of the world.

Acknowledgements I am grateful to Bill Brewer for very helpful written comments and discussion and to Dominic Alford-Duguid and David Jenkins for helpful comments. I presented a forerunner of the paper in a summer seminar in King's College: many thanks to all participants for their feedback. I owe special thanks to two referees who both provided extensive comments which led me to rethink the paper.

Open Access This article is distributed under the terms of the Creative Commons Attribution 4.0 International License (http://creativecommons.org/licenses/by/4.0/), which permits unrestricted use, distribution, and reproduction in any medium, provided you give appropriate credit to the original author(s) and the source, provide a link to the Creative Commons license, and indicate if changes were made.

\footnotetext{
22 See Soteriou $(2011,193)$.

${ }^{23}$ See Soteriou $(2011,193)$ and Richardson $(2009,238)$.
} 


\section{References}

Burge, T. (2010). Origins of objectivity. Oxford: Oxford University Press.

Campbell, J. (2011). Review of Tyler Burge's origins of objectivity. The Journal of Philosophy, 108, 269-285.

Cassam, Q. (2014). Representationalism. In Campbell, J. \& Cassam, Q. 2014, 158-79.

Conrad Martius, H. (1916). Zur Ontologie und Erscheinungslehre der realen Außenwelt. Verbunden mit einer Kritik positivistischer Theorien. Jahrbuch für Philosophie und phänomenologische Forschung, 3.

Duncker, K. (1947). Phenomenology and the epistemology of consciousness. Philosophy and Phenomenological Research, 7, 505-542.

Evans, G. (1980). 'Things without the mind'. Reprinted in his Collected Papers (pp. 249-291). Oxford: Oxford University Press 1985.

Evans, G. (1982). The varieties of reference. Oxford: Oxford University Press.

Gelb, A. (1929). Die Farbenkonstanz: der Sehdinge. In W. A. von Bethe (Ed.), Handbuch normalen und pathologische Psychologie (pp. 594-678). Berlin: Springer.

Hering, E. (1905). Die Lehre vom Lichtsinn. Leipzig: Wilhelm Engelmann.

Hofmann, H. (1919). Empfindung und Vorstellung. Berlin: Reuther and Reinhard.

Hopp, W. (2011). Perception. In S. Luft \& S. Overgaard (Eds.), The routledge companion to philosophy (pp. 146-158). London: Routledge.

Husserl, E. (1898). Abhandlung über Wahrnehmung von 1898. In his Wahrnehmung und Aufmerksamkeit. Texte aus dem Nachlass (1893-1912). Husserliana 38. Dordrecht: Springer 2004, 123-59.

Husserl, E. (1904/5). Hauptstücke aus der Phänomenologie und Theorie der Erkenntnis. Vorlesungen aus dem Wintersemester 1904/5. In his Wahrnehmung und Aufmerksamkeit. Texte aus dem Nachlass (1893-1912), $3-123$.

Husserl, E. 1907. Ding und Raum Vorlesungen 1907. Husserliana 16. Ed. by U. Claesges. Den Haag: Martinu Nijhoff 1973.

Husserl, E. (1913a). Logische Untersuchungen (Second ed.). Tübingen: Max Niemeyer.

Husserl, E. (1913b). Ideen zur reinen Phänomenologie und phänomenologischen Forschung. Jahrbuch für Philosophie und Phänomenologische Forschung 1, 1-323. Transl. 1933 by Boyce Gibson as Ideas: General Introduction to Phenomenology. Reprint London: Routledge 2012.

Husserl, E. (1928). Vorlesungen zur Phänomenologie des inneren Zeitbewusstseins. Ed. by M. Heidegger. Halle: Niemeyer.

Ingarden, R. (1930, 1972). Das Literarische Kunstwerk. (Fourth ed.). Tübingen, Max Niemeyer.

Katz, D. (1911). Die Erscheinungsweise der Farben und ihre Beeinflussung durch die individuelle Entwicklung. Leipzig: Barth.

Kelly, S. (2010). The normative nature of perception. In B. Nanay (Ed.), Perceiving the world (pp. 146-160). Oxford: Oxford University Press.

Linke, P. (1928). Grundfragen der Wahrnehmungslehre. München: Ernst Reinhardt.

Madary, M. (2010). Husserl on Perceptual Constancy. European Journal of Philosophy, 20, 145-165.

Mulligan, K. (1995). Perception. In B. Smith \& D. Smith (Eds.), The Cambridge Companion to Husserl (pp. 168-238). Cambridge: Cambridge University Press Cambridge.

Richardson, L. (2009). Seeing empty space. European Journal of Philosophy, 18, 227-243.

Schuhmann, K. (1977). Husserl Chronik: Denk- und Lebensweg Edmund Husserls. Den Haag: Martinus Nijhoff.

Siegel, S. (2006). Direct realism and perceptual consciousness. Philosophy and Phenomenological Research, $73,378-409$.

Smith, A. D. (2002). The problem of perception. Cambridge: Mass. Harvard University Press.

Soteriou, M. (2011). The perception of absence, space and time. In J. Roessler, H. Lerman, \& N. Eilan (Eds.), Perception, causation, and objectivity (pp. 181-206). Oxford: Oxford University Press. 